\title{
A COMPARATIVE STUDY OF EFFICACY OF CALCIUM + VITAMIN D3 AND CALCIUM + VITAMIN D3 + VITAMIN K2 IN PREVENTION OF OSTEOPOROSIS IN POSTMENOPAUSAL OSTEOPENIC WOMEN WHO ARE ADOPTING A SEDENTARY PATTERN OF LIFE STYLE
}

\author{
Verma. V. K, Verma Hemlata, Gandhi Kusum.
}

\author{
1. Associate Professor, Department of Orthopedics, Peoples College of medical science and research centre, Bhopal, \\ Madhya Pradesh. \\ 2. Assistant Professor, Department of Pharmacology, Gandhi Medical College, Bhopal. Madhya Pradesh. \\ 3. Assistant Professor, Department of Anatomy, Rural Medical College, PIMS, Loni. Maharashtra.
}

\author{
CORRESPONDING AUTHOR: \\ Dr. Verma Hemlata / Dr. Verma V. K, \\ HIG C-6, \\ PCMS Campus, Bhanpur, \\ Bhopal. Pin- 46203. \\ E-mail: vkverma0505@gmail.com
}

\begin{abstract}
OBJECTIVE:- The aim of the study was to determine the efficacy of combination of vitamin $\mathrm{K} 2+$ vitamin $\mathrm{D} 3+$ calcium in prevention of osteoporosis in osteopenic postmenopausal women . MATERIALS AND METHODS: This study included 60 postmenopausal osteopenic women. They were divided in two groups one group were administered $1 \mathrm{gm}$ calcium+ vitamin D3 $1 \mathrm{mcg} /$ day and other group were administered 1gm calcium+ vitamin D3 1mcg+vitamin K2 45mg/day. All the patients were investigated for bone marker undercarboxilated osteocalcin, N Telopeptide and bone mineral density. RESULTS: It was observed that group I that was treat with vitamin D3+calcium had less percentage improvement in bone mineral density and reduction of undercarboxilated osteocalcin and $\mathrm{N}$ telopeptide in comparison to patients who were treat with vitamin $\mathrm{K} 2+$ vitaminD3+calcium observed had more percentage improvement in bone mineral density and reduction of undercarboxilated osteocalcin and N telopeptide. CONCLUSION-According the results of this study vitamin $\mathrm{K} 2$ to be more effective as a protective agent than combined calcium and vitamin D3 administration in cases of osteoporosis.
\end{abstract}

KEY WORD: osteoporosis, osteopenia, vitamin K, vitamin D, BMD, uc(OC) N telopeptide.

INTRODUCTION: Osteoporosis, a condition characterized by decrease bone strength is prevalent among postmenopausal women, with underlying condition or major risk factors associated with bone demineralization (2397 Harisson's 17 edition). Osteoporosis is one of the major health problems in elderly and postmenopausal women in modern world A sedentary life style reduces the constant forces that bone need s to experience in order to continue its normal process of remodeling (15) (Akhter 2010). Immobilization leads to rapid loss of bone mass. Longterm immobilization can have serious skeletal consequences and may lead to increased fracture liability. Most cases of disuse osteoporosis require a long time for bone to recover its bone mineral density and strength. Hence we have to keep in mind that there are no treatments better than prophylaxis for disuse osteoporosis (14). (Takata S, yasui N. Disuse osteoporosis, J Med Invest 2001; 48:147-156). 
WHO operationally define osteoporosis as a bone density that falls - 2.5 standard deviations (SD) below the mean for young healthy adult of same gender. Postmenopausal women who fall at the lower end of the young normal range (T-score of $>1$ SD below the mean between -1 to 2.5 SD) are defined as having low bone mineral density (osteopenia) and are also at increased risk of osteoporosis.

Osteoporosis, a multifactorial pathology has been reviewed extensively; A review by Gaby of nutritional and hormonal management of osteoporosis is an excellent and well referred source.

Evaluation of the etiology of osteoporosis in particular individuals can involve hormonal aspect, exercise patterns, nutrients intakes, digestion and nutrients absorption.

The balance between the resorption and formation change with age and sex. Bone turnover take place by many nutrients as calcium, vitamin $\mathrm{D}_{3}$ and vitamin $\mathrm{K}$. Adequate calcium intake is considered as one of the important nutritional factors to establish peak bone mass. Vitamin D which is essential for optimal dietary Ca absorption should be sufficient as well.

Vitamin K2 exerts a powerful influence on bone building, especially in osteoporosis, and has been cited as one of the most frequently prescribed treatment for osteoporosis.

Various form of vitamin K are transformed into K2 in the femur. Vitamin K2 has been shown to be the most important inducer of bone mineralization in human osteoblasts (16) Yamaguchi M, Taguchi H L et al.).Vitamin K2 in combination with 1-alpha-25-dihydroxyvitamin $\mathrm{D}_{3}$ has also been shown to increase osteocalcin production alpha 1,25(OH)2 vitamin D3 induced mineralization in human periosteal osteoblast)(17) Koshihara Y, Hoshi K, Ishibashi H, Shikari M JVitamin K2 promates 1. Application of $\mathrm{K} 2$ result in gamma-carboxylation of 1-alpha-25-dihydroxyvitamin D3- induced osteocalcin, which in turn is able to deposit gamma-carboxyglutamic acid-containing osteocalcin to the extracellular matrix on human osteoblast. In vitro studies using assays from various species demonstrate vitamin K2 inhibits osteoclastogenesis of bone. Undercarboxylation of the bone matrix protein osteocalcin appears to be a sensitive measure of vitamin $\mathrm{K}$ status. When defined as elevated concentrations of undercarboxylated osteocalcin ( $\mathrm{ucOC}$ ), vitamin $\mathrm{K}$ insufficiency appears to be common in postmenopausal women. High serum ucOC concentration has been associated with skeletal turnover (12) low bone mineral density, and increased risk of osteoporotic fractures(13).N Telopeptide, the amino terminal cross-linked peptide of type I collagen is released during bone resorption and has been correlated with BMD T-Score(11)

METHODS AND MATERIALS: The study began in June 2010 and ended in June 2011.We studied 60 postmenopausal women, with mean age 50 years and normal body mass index having no other concurrent illness. Subjects were recruited from urban areas all subjects were working women whose working hours were 10-12 hr and during work they had to sit at least 9-10 hr. They had bone mineral density between - 2.5 to -1.0 T-score (osteopenia). Patients were included according to their Bone mineral density, and bone marker. Measurement of bone mineral density done by Dual energy x-ray absorptiometry (DEXA) at spine and hip bone, and laboratory studies were performed before starting the treatment, after the 6 month of treatment and after the completion of treatment. Measurement of bone turnover marker was done by commercially available specific kit. NTelopeptide (NTx) bone resorption marker in urine was measured with a commercially available ELISA. Measurment of undercarboxylated osteocalcin in serum was measured by ELISA with IRMA. Samples were collected early morning. 
STUDY DESIGN: In this study subjects were randomized into two group one group receive calcium 1 gram/day + Vit. $D_{3} 1 \mathrm{mcg} /$ day and another group received calcium 1 gram day $+V$ it $D_{3} 1 \mathrm{mcg} /$ day + vit. $\mathrm{K}_{2} 45 \mathrm{mg} /$ day. Subjects were aware of their random assignment to receive medication. Compliance with study preparation was evaluated by tablet counts by 1 and 2 weeks. Serum and plasma were obtained at baseline, 6 weeks, 6 month and 1 year. Blood samples were obtained by routine venipuncture between $0800 \mathrm{hr}$ and $1100 \mathrm{hr}$ after subjects fasted for $\geq 8 \mathrm{hr}$. Bone mineral density also done at baseline, 6 weeks, 6 month and 1 year. Statistical analysis -For analysis of baseline characteristics, we included data from all subjects For analyses involving changes over time ,we analyzed data separately by treatment group. Descriptive statistics are presented as the mean \pm SD unless otherwise noted. Study groups were defined by treatment and age. Baseline comparisons of variables between groups were performed by using Student $t$ test.Change over time in serum \% of BMD, N-Telopeptide, undercarboxylated osteocalcin was evaluated by repeated-measures analysis of variance (ANOVA) with full interaction.

\section{RESULT:}

GROUP I: Baseline characteristic were measured mean age was 49.23 \pm 3.25 .Body mass index was $22.1 \pm 2.15$, Bone mineral density was $-1.70 \mathrm{SD}$ and bone markers N Telopeptide(NTx) was $20.6 \mathrm{~nm} / \mathrm{l}$ BCE (nanomoles per $\mathrm{L}$ of bone collagen equivalents)and undercarboxylated osteocalcin was $8.2(\mathrm{ng} / \mathrm{ml})$ After the 6 week treatment of calcium and vitamin $\mathrm{D}_{3}$ there is only $0.29 \%$ improvement in bone mineral density and $17.28 \%$ at 6 month,17.84\% at 1 year improvement respectively. Reduction of $\mathrm{N}$ Telopeptide at 6 week of base line was $7.04 \%, 11.37 \%$ at 6 month and $14.84 \%$ at 1 year of treatment. Undercarboxylated osteocalcin was reduced $2.68 \%, 4.81 \%$ and $7.39 \%$ at 6 week, 6 month and 1 year respectively.

GROUP I: One way ANOVA Table (variation between groups)

\begin{tabular}{|l|l|l|l|l|l|l|}
\hline Group & Base line & 6 weeks & 6 Months & 1 Years & F-Value & P value \\
& Mean \pm SD & Mean \pm SD & Mean \pm SD & Mean \pm SD & & \\
\hline BMD & $-1.71 \pm 0.705$ & $-1.70 \pm 0.208$ & $-1.41 \pm 0.296$ & $-1.16 \pm 0.651$ & 8.001 & $<0.0001^{*}$ \\
\hline NTx & $20.65 \pm 1.02$ & $20.18 \pm 1.06$ & $19.85 \pm 1.02$ & $19.68 \pm 1.09$ & 5.017 & $0.003^{*}$ \\
\hline Uc(OC) & $8.93 \pm 0.341$ & $8.69 \pm 0.344$ & $8.50 \pm 0.398$ & $8.27 \pm 0.539$ & 13.799 & $<0.0001^{*}$ \\
\hline
\end{tabular}




\section{ORIGINAL ARTICLE}

GROUP 1

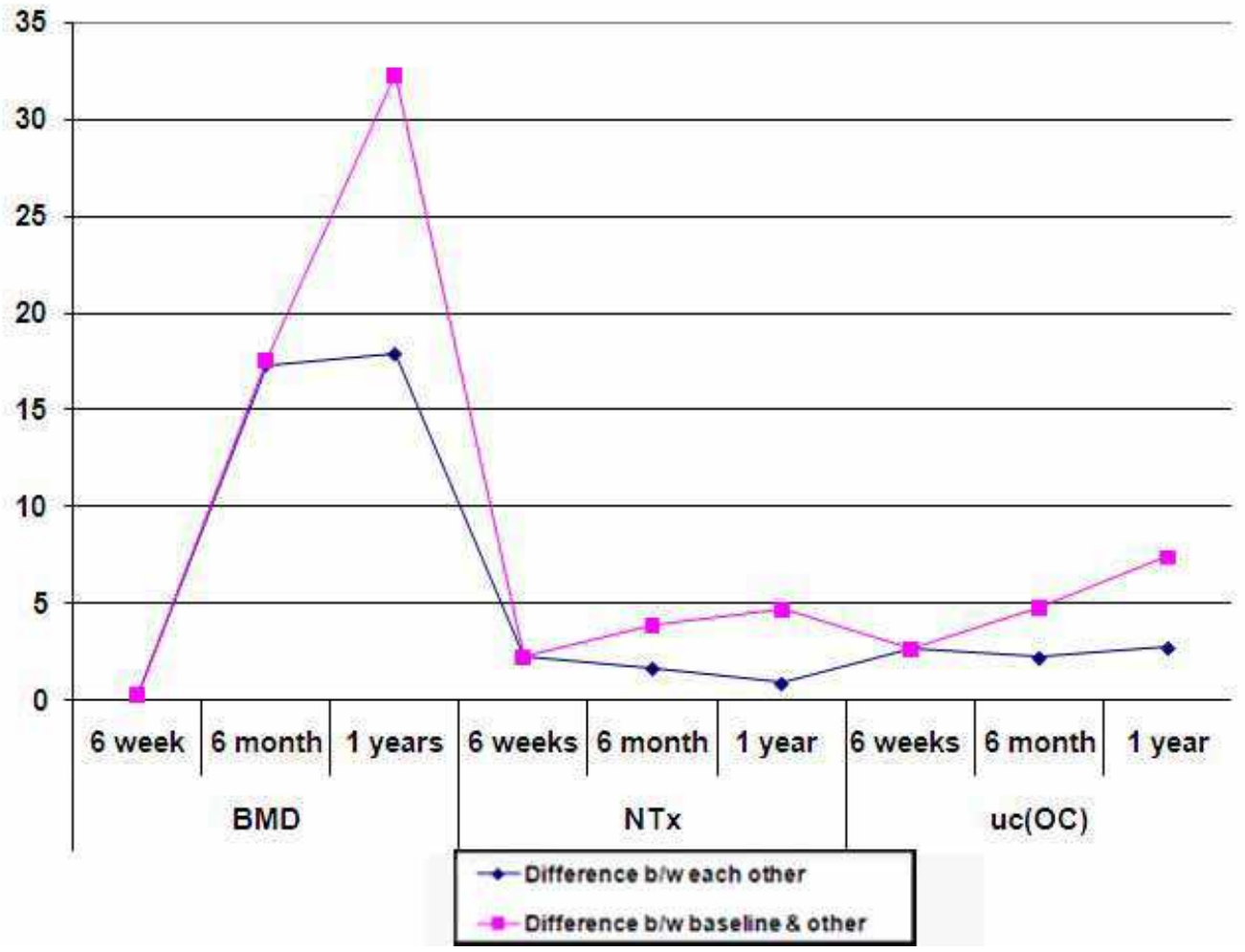

GROUP II - Baseline characteristic were measured mean age was 50.56 year (SD 3.18),Body mass index was $21.7 \mathrm{~kg} /$ body wt.(SD 1.99).After treatment with calcium +vitamin $\mathrm{D}_{3}+\mathrm{Vitamin} \mathrm{K}_{2}$ the improvement in BMD was 9.74\%,35.44\% and $47.65 \%$ of base line at 6 week, 6 month and 1 year respectively. Serum NTx was reduced $7.04 \%, 11.37 \%$ and $14.84 \%$ of baseline at 6 week, 6 month and 1 year respectively. Undercarboxylated osteocalcin was reduced $13.42 \%, 26.61 \%$ and $34.20 \mathrm{Gro} \%$ of baseline at 6 week, 6 month and 1 year respectively.

GROUP II: One way ANOVA Table (Variation between groups)

\begin{tabular}{|l|l|l|l|l|l|l|}
\hline Group & $\begin{array}{l}\text { Base line } \\
\text { Mean } \pm \text { SD }\end{array}$ & $\begin{array}{l}6 \text { weeks Mean } \\
\pm S D\end{array}$ & $\begin{array}{l}6 \quad \text { Month } \\
\text { Mean } \pm S D\end{array}$ & $\begin{array}{l}1 \text { Years Mean } \\
\pm S D\end{array}$ & F-Value & P-Value \\
\hline BMD & $-1.61 \pm 0.268$ & $-1.45 \pm 0.616$ & $-1.04 \pm 0.772$ & $-0.84 \pm 0.390$ & 12.662 & $<0.0001^{*}$ \\
\hline NTx & $21.10 \pm 0.832$ & $19.62 \pm 2.025$ & $18.70 \pm 0.909$ & $17.97 \pm 0.898$ & 34.0190 & $<0.0001^{*}$ \\
\hline Uc(OC) & $8.64 \pm 0.462$ & $7.48 \pm 0.519$ & $6.34 \pm 0.456$ & $5.69 \pm 0.387$ & 242.066 & $<0.0001^{*}$ \\
\hline
\end{tabular}




\section{ORIGINAL ARTICLE}

\section{GROUP 2}

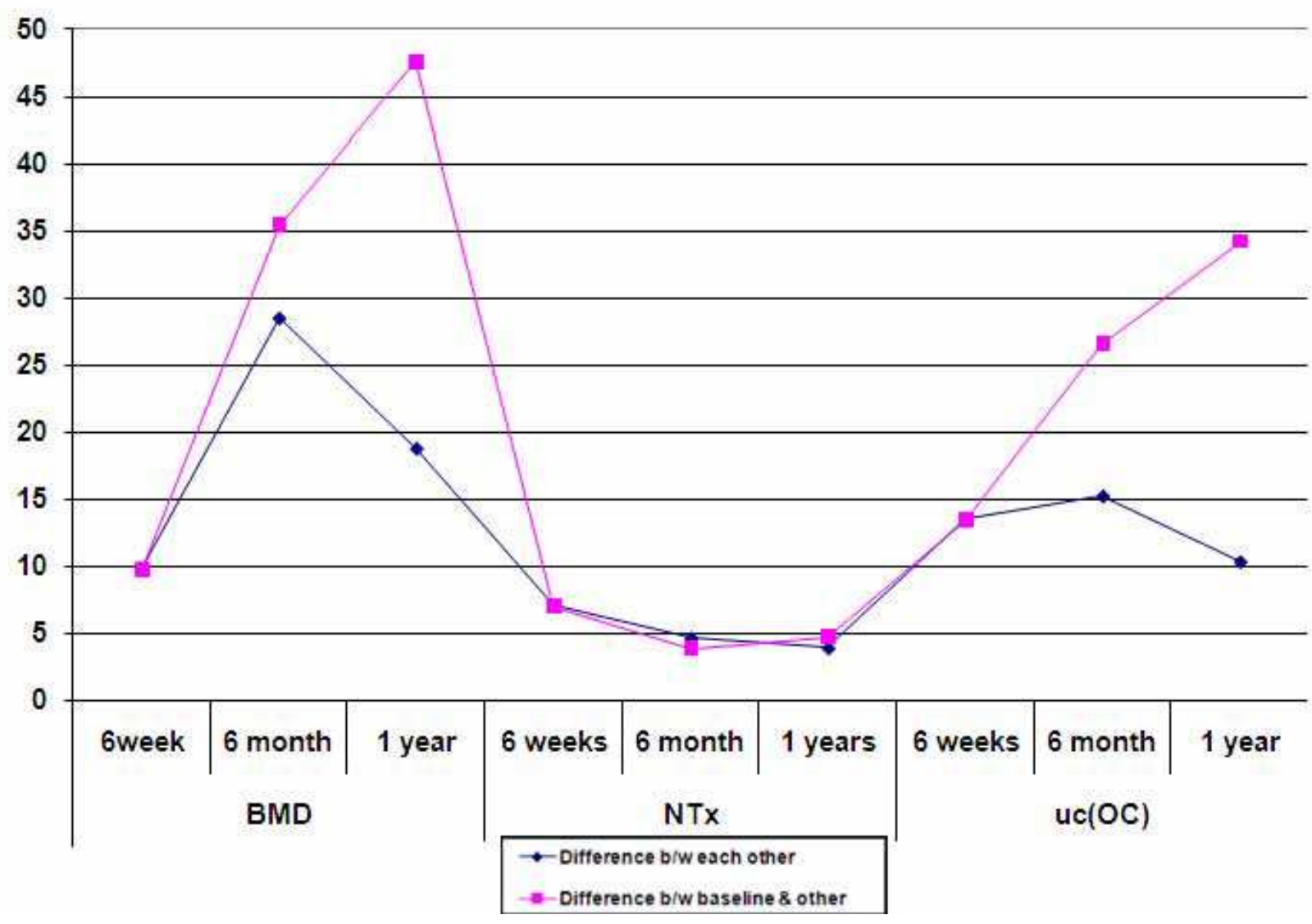

COMPARISON BETWEEN GROUPS :

\begin{tabular}{|l|l|l|l|l|}
\hline Group & Group I Mean \pm SD & Group II Mean \pm SD & T-Value & P-Value \\
\hline BMD & $-1.16 \pm 0.651$ & $-0.84 \pm 0.390$ & 2.2730 & 0.0267 \\
\hline NTx & $19.68 \pm 1.09$ & $17.97 \pm 0.898$ & 6.6146 & $<0.0001$ \\
\hline Uc(OC) & $8.27 \pm 0.539$ & $5.69 \pm 0.387$ & 21.3025 & $<0.0001$ \\
\hline
\end{tabular}

DISCUSSION: :In this study administration of vitamin K2 +vitamin D3+calcium increase bone mineral density and reduced \% ucOC in all women. Dietary intake provide inadequate vitamin $\mathrm{K}$ at the age of menopause due to $\uparrow$ requirements and $\downarrow$ absorption and synthesis allow maximal osteocalcin carboxilation.Accumulating evidence suggest that vitamin $\mathrm{K}$ insufficiency contribute to development of osteoporosis. However much of this evidence is based on submaximal osteocalcin $\gamma$ carboxilation ie. Elevated ucOC was associated with low bone mass.(1)This observation in our study is to some extent congruent with the recent finding that vitamin $\mathrm{K}$ depletion led to increased bone turnover as measured by serum undercarboxylated osteocalcin, urinary NTx concentration and bone mineral density(2).These markers were subsequently normalized by vitamin $\mathrm{K}$ administration on the basis of our observation we speculated that vitamin $\mathrm{K}$ insufficiency impairs the function of the 
calcium(3).In our study finding are supported by evidence that intake of vitamin $\mathrm{K}$ can lower serum concentration of uc(OC) and the uc(OC) is positively associated with risk of osteoporosis. Vergnaud et al reported a significantly elevated odd ratio of 1.9 in women the highest quartile of percentage of uc(OC) after adjustment for bone mineral density(3,4).In our study we observed a significant interaction between Vitamin D and Vitamin $\mathrm{K}$ intake. Evidence that Vitamin D stimulate the gama carboxylation of gama carboxyglutamyl -containing proteins(5).promotes osteocalcin synthesis(5,6).and decreased uc(OC)(7)suggested that vitamin D may be a necessary component of the vitamin $\mathrm{K}$ dependent carboxylation process in bone. Theoretically this finding can be explain by the effect of two vitamins on calcium homeostasis vitamin D acts as an inducer of bone resorption and thus higher intake may result in increased turnover and increased urinary calcium execration. Conversely results of some studies in animal(8) and humans(9) indicate that vitamin $\mathrm{K}$ decrease urinary calcium execration. Thus despite high dietary intake of vitamin $\mathrm{D}$ there may be an increased risk of hip fracture when vitamin $\mathrm{K}$ intake are low. Studies shows that both man and women engage in regular exercise have much lower risk of osteoporosis and fracture(Ebeling 2004,englund 2011).

CONCLUSION: It was concluded that vitamin k provided protective effects in diminishing bone loss. Combined administration of vitamin $\mathrm{k}$, vitamin $\mathrm{D}$ and calcium is more effective then vitamin $\mathrm{D}$ and calcium.

ACKNOWLEDGMENTS: We are giving to cordially thanks of all the patients for their cooperation and gives a good compliance in their busy schedule.

\section{REFERENCES:}

1. Szule P, ChapuyMC, MecenierPJ, Delmas PD. Serum undercarboxylated osteocalcin is a marker of hip fracture :a three year follow up study.Bone 1996;18:487-8

2. Binkly N, Engelk J, KraegerD,Osteocalcin Mog participate in calcium homeostasis. J Bone. calcium homeostasis. Bone 3Parfitt.AM,Bone and plasma 1987 (suppl):57-8

3. Knapen $\mathrm{MHJ}$, Hamulyak $\mathrm{K}$, Vermeer $\mathrm{C}$. The effect of vitamin $\mathrm{K}$ supplementation on circulatory osteocalcin and urinary calcium execration .Ann Intern Med.1989;111;1001-5

4. Dauglees AS, Robins SP, Hutchison JD, Porter RW, Stewart A, Reid DM, carboxylation of osteocalcin in postmenopausal osteoporotic women following vitamin $\mathrm{K}$ and $\mathrm{D}$ supplementation. Bone 1995;17;15-20

5. Deyl Z, Adam M. Evidance for vit. D dependent gamma carboxylation in osteocalcin related protein. Biochem Biophys Res Commun1983; 113; 299-300.

6. Price PA Baukal SA 1-25 Dihydroxyvitamin D3 increase synthesis of vitamin $\mathrm{K}$ dependent bone protein by osteosarcoma cells. J Boil chem. 1980; 255;11660-3

7. Szule P. Delmas PD influence of vitamin D and retinoids on gamma carboxylation of osteocalcin in human osteosarcoma MG 63 cells-bone 1996;19;615-20

8. Kon Siong GJ Hamulyank K Gijsbears BL Roumen FJ, Vermeer C effects of vitamin K and oral anticoagulants on urinary calcium excretion. Br J Haematal 1993;83;100-4

9. chloz- Ahrens KE. Bohme P. Schrezemmeir J Milchforscheeng BF vitamin K deficiency affects calcium retention, bone mineralization and $\mathrm{Ab} \square$ in growing and ovarectomized rats. osteoporosis int.1996 


\section{ORIGINAL ARTICLE}

10. Harisson's 17 edition;2397

11. Schneider DL and Barrett-Connor EL; urinary N.telopeptide level discriminate normal osteopenic and osteoporotic bone mineral density. Arch Intern Med 157; 1241; $1245,1997$.

12. Kanepan MH, Jie KS Hamulyak k, VermeerC, Vitamin K-induced changes in markers for osteoblast activity and urinary calcium loss.Calcif Tissue Int 1993;53:81-5

13. Szule P, Chapuy MC, Meunier PJ. Delmas PD. Serum undercarboxylated osteocalcin is a marker of the risk of hip fracture in elderly women. J Clin Invest 1993; 91:1769-74.

14. Takata S,yasui N. Disuse osteoporosis ,J Med Invest 2001; 48:147-156.

15. Akhter 2010

16. Yamaguchi M,Taguchi H L et aI.

17. Koshihara Y,Hoshi K,Ishibashi H,Shikari M. 